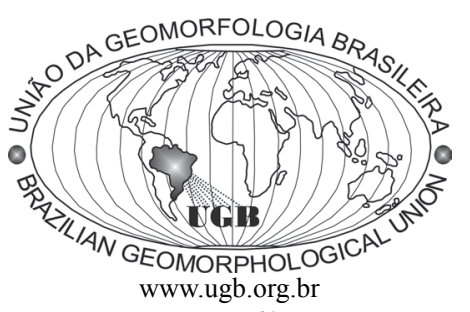

\title{
EVOLUÇÃO TECTÔNICA E DENUDACIONAL DA SERRA DO MAR (SE/BRASIL) NO LIMITE ENTRE O CRETÁCEO SUPERIOR E PALEOCENO, UTILIZANDO ANÁLISES DE TRAÇOS DE FISSÃO E U-TH/HE EM APATITAS
}

\author{
Marli Carina Siqueira Ribeiro \\ Instituto de Geociências e Ciências Exatas, Departamento de Petrologia e Metalogenia, Unesp - Avenida 24 A \\ número 1515 - Caixa Postal 178 - CEP 13.506-900 - Rio Claro/SP, Brasil-e-mail: marlicarina@gmail.com. \\ Peter Christian Hackspacher \\ Instituto de Geociências e Ciências Exatas, Departamento de Petrologia e Metalogenia, Unesp - Avenida 24 A \\ número 1515 - Caixa Postal 178 - CEP 13.506-900 - Rio Claro/SP, Brasil - e-mail: phack@rc.unesp.br \\ Luiz Felipe Brandini Ribeiro \\ Pesquisador do Instituto de Geociências - Unicamp, Campinas/SP, Brasil - e-mail: lfbrvm@yahoo.com.br \\ Julio César Hadler Neto \\ Instituto de Física Gleb Wataghin, Unicamp, Caixa Postal 6152 - CEP 13.081-970 - Campinas/SP, Brasil - \\ e-mail: hadlerneto.ifi@unicamp.br
}

\begin{abstract}
Resumo
Neste trabalho foram associadas às idades de traços de fissão em apatitas (TFA) e idades (U-Th)/He em perfil vertical na porção centro-sul da Serra do Mar (Sudeste/Brasil), o qual foi associado com um rápido soerguimento tectônico entre o Cretáceo Superior e Paleoceno. Estes processos tectônicos foram responsáveis pela fragmentação das morfologias, sendo estas posteriormente denudadas formando os níveis de paleossuperfícies presentes atualmente.
\end{abstract}

Palavras-chave: Serra do Mar; traços de fissão em apatitas; (U-Th)/He; tectônica cenozoica.

\begin{abstract}
In this paper we combined results from Apatite Fission Track (AFT) and (U-Th)/He ages in a vertical profile in the Southern Central portion of the Serra do Mar (Southeast Brazil), which was associated with a rapid tectonic uplift during the Late Cretaceous and the Paleocene. These tectonic processes were responsible for the fragmentation of the morphologies which were later denudated, creating the palaeosurface levels currently present.
\end{abstract}

Keywords: Serra do Mar; Apatite Fission Tracks; (U-Th)/He; cenozoic tectonic.

\section{Introdução}

Os relevos que compõem a margem passiva do Sudeste brasileiro têm seus aspectos físicos relacionados à sua evolução durante os períodos Mesozoico e Cenozoico, sendo esta marcada pela interação entre os processos tectônicos, isostáticos e climáticos. Registros sobre a atuação dos eventos tectônicos e climáticos, principalmente durante o Cretáceo Superior e o Paleoceno contribuíram de maneira significativa na história evolutiva das morfologias que compõem a Região Sudeste do Brasil. 
As contribuições destes processos durante os período Cretáceo Superior e o Paleoceno têm sido amplamente descritos na literatura. Vários trabalhos retratam a importância do período Cenozoico na formação do arcabouço morfotectônico dos relevos que compõem a margem passiva do Sudeste brasileiro (ALMEIDA \& CARNEIRO, 1998, GONTIJO, 1999, MODENESI et al., 2002, RICCOMINI et al., 2004, ZALÁN \& OLIVEIRA, 2005; etc.), discutindo a importância das feições indicativas de soerguimento tectônico que desnivelaram as morfologias durante este período. Indícios destas reativações cenozoicas, de acordo com Riccomini et al., (2004) e Zalán \& Oliveira (2005), são representados morfologicamente através dos planaltos que representam blocos tectonicamente soerguidos durante a tafrogênese cenozoica que culminou com a instalação do Rift Continental do Sudeste do Brasil, interrompendo a instalação de ciclos erosivos na área.

A aplicação da análise de traços de fissão em apatitas (ATFA) na porção sudeste da margem passiva brasileira tem abordado detalhadamente a problemática sobre a evolução tectono-denudacional do Cenozoico no sudeste brasileiro (HACKSPACHER et al., 2004, 2007, FRANCO et al., 2005, RIBEIRO et al., 2005, SIQUEIRA-RIBEIRO, 2007), o que tem gerado questões sobre a necessidade de se reavaliar os processos extensionais no limite Cretáceo Superior-Paleoceno nas áreas cristalinas (HACKSPACHER et al., 2006).
Neste trabalho foram utilizadas técnicas de mapeamento geomorfológico para a identificação dos principais de níveis de paleossuperfícies, sobre as quais foram selecionadas amostras para a datação através da Análise de Traços de Fissão em Apatitas (ATFA) e a sistemática (U-Th)/He em apatitas.

Os resultados obtidos por meio das análises geomorfológicas, juntamente com os métodos termocronológicos por traços de fissão e (U-Th)/He em apatitas registraram episódios térmicos associados ao soerguimento tectônico no Cretáceo Superior e Paleoceno nas morfologias que compõem a Serra do Mar.

\section{Contexto geológico e geomorfológico regional}

Aárea de estudo está inserida na Província Mantiqueira, definida por Almeida et al., (1977, 1981), sendo esta formada por uma série de fragmentos crustais de diferentes idades e evoluções tectônicas situados no Sul e Sudeste do Brasil, envolvendo as faixas Ribeira, Dom Feliciano e São Gabriel, e pela zona de interferência entre os orógenos Brasília e Ribeira (CAMPANHA \& SADOWSKI, 1999). Geologicamente, a área de estudo (Figura1) está situada no Cinturão Ribeira, setor este cortado por zonas de cisalhamento de direções nordeste, as quais separam os blocos tectônicos que estão inseridos os terrenos Juiz de Fora, Costeiro, Apiaí, Embu, Socorro-Guaxupé (HEILBRON et al., 2000).

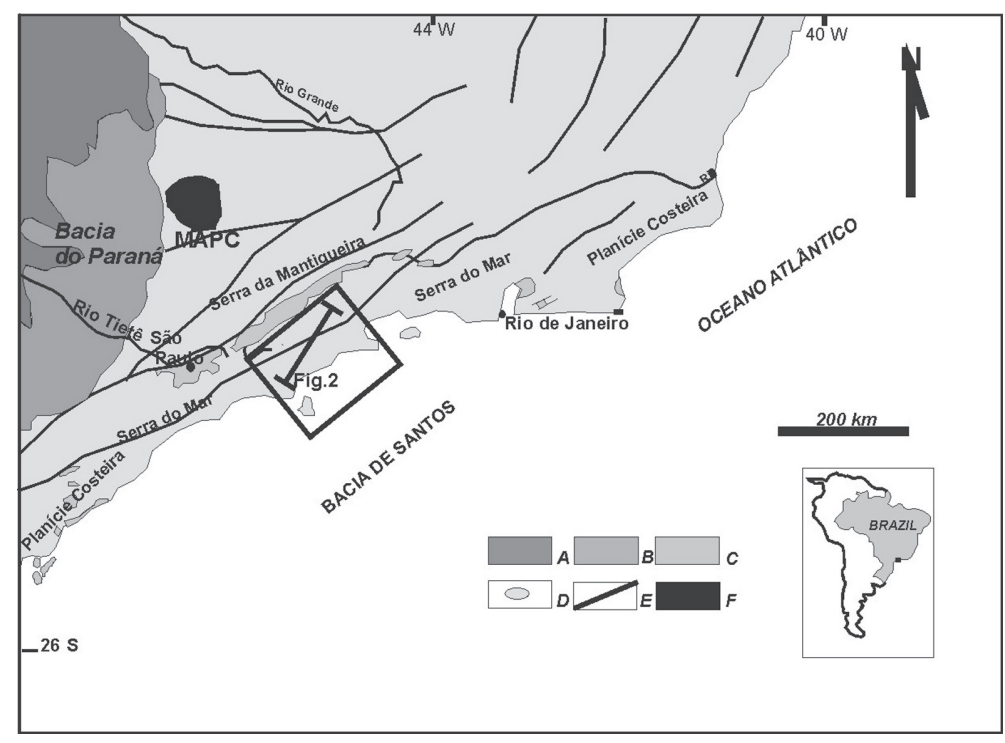

Figura 1 - Contexto geológico regional da área de estudo. (a) Rochas vulcânicas toleíticas Eocretáceas da Formação Serra Geral, (b) Sedimentos Paleozoicos da Bacia do Paraná, (c) Rochas Pré-Cambrianas, (d) Sistema de Rifts Cenozoicos, (e) Zonas de cisalhamento pré-cambrianas, (f) Maciço Alcalino de Poços de Caldas. Modificado de Melo et al., (1985) e Riccomini et al., (2004). Detalhe do perfil topográfico apresentado na Figura 2. 
Os primeiros registros de reativações tectônicas mesozoicas ocorreram a partir do Jurássico Superior e do Cretáceo Inferior, marcando o início da Reativação Wealdeniana (ALMEIDA, 1969, 1983). Esta manifestação tectônica caracterizou-se sobretudo pela reativação de antigos falhamentos, ocasionando o soerguimento de relevos, abatimentos de bacias costeiras e acentuada subsidência da Bacia do Paraná. A cronologia relacionada à ruptura do Gondwana compreende o período compreendido entre 140-130 Ma com idades fornecidas por meio das datações de rochas vulcânicas do expressivo derrame de lavas da Bacia do Paraná, que ocorrem sobrepostas a rochas cristalinas pré-cambrianas e paleozoóicas no Continente e presentes no substrato da Bacia de Santos (MIZUSAKI et al., 1994; PEREIRA \& FEIJÓ, 1994; TURNER et al., 1994, VIEIRA et al., 1994; RENNE et al., 1996; HAWKESWORTH et al., 2000, MIO, 2006). Além do magmatismo toleítico, ocorreu outra atividade ígnea de natureza alcalina nas bordas da Bacia do Paraná, a qual foi iniciada no Cretáceo Inferior estendendo-se até o Terciário (ALMEIDA, 1983; RICCOMINI et al., 2004a, b; MARQUES \& ERNESTO, 2004).

Na porção formada pela Serra do Mar, os enxames de diques de diabásio possuem direções principais NE-ENE e outras filiações toleíticas são particularmente frequentes e extensas (ALMEIDA, 1986), demonstrando sua contemporaneidade aos derrames vulcânicos da Formação Serra Geral na Bacia do Paraná e ao enxame de diques presentes no Arco de Ponta Grossa, apresentando direção NW-SE, com idades K-Ar e Ar-Ar entre 139 e 125 Ma (TURNER et al., 1994; RENNE et al., 1996).

Nas bacias marginais de Santos e Campos, ambas situadas na porção sudeste brasileira, o magmatismo toleítico com datações de K-Ar que registraram idades entre 134 e $121 \mathrm{Ma}$ (Mizusaki et al., 1988; MIZUSAKI \& THOMAZ FILHO, 2004).

O magmatismo alcalino mesozoico-cenozoico na Província da Serra do Mar possui Idade Neocretácea, sendo este controlado por falhas de direção NE a ENE e relacionados, ao desenvolvimento da Serra do Mar e da Bacia de Santos (RICCOMINI et al., 2004a). Na área que compõe o Litoral Norte do Estado de São Paulo, este episódio de magmatismo alcalino é formado por uma série de intrusões alcalinas situadas nas ilhas de São Sebastião, apresentando os corpos de maior representatividade e outros menores, como as das ilhas Montão de Trigo, Búzios e Vitória. Na porção mais ao sul, entre os limites entre os estados de São Paulo e Paraná, na região próxima ao Arco de Ponta Grossa, ocorrem as intrusões de Cananéia, Barra do Teixeira e Mato Preto.

A Província do Alinhamento Magmático de Cabo Frio (ALMEIDA, 1991) se desenvolveu ao longo de uma extensa zona de fratura transcorrente sinistral, com direção principal WNW, associada a duas fases de reativação e magmatismo, a primeira durante o Neocretáceo ao Paleoceno e a segunda durante o Eoceno (RICCOMINI et al., 2005).
Na região que perfaz parte do Rift Continental do Sudeste do Brasil, descrito por Riccomini (1989), essas rochas integram as províncias do Arco de Ponta Grossa, Serra do Mar (ALMEIDA, 1983) e do Alinhamento Magmático de Cabo Frio (ALMEIDA, 1991).

Dentro do cenário estrutural regional, uma importante feição denominada primeiramente por Almeida (1976) de Sistema de Rifts da Serra do Mar é composta por complexos vales tectônicos, áreas montanhosas soerguidas por falhas e bacias sedimentares de origem tectônica. Posteriormente, Riccomini (1989) propôs a designação de Rift Continental do Sudeste do Brasil (RCSB), o qual é composto por uma feição tectônica de idade cenozoica, caracterizada por uma faixa estreita, deprimida e alongada, com direção principal ENE. Em seu cenário atual, o RCSB (RICCOMINI et al., 2004b) é dividido em três segmentos. O primeiro perfaz a parte ocidental que engloba a Bacia de Curitiba, os grábens de Guaraqueçaba, Sete Barras e Cananéia, o segundo segmento composto pelas bacias de São Paulo, Taubaté, Resende e Volta Redonda, além das ocorrências menores de Bonfim e do Cafundó, e o terceiro segmento constituído pelo Gráben de Guanabara, que aloja as bacias do Macacu, Itaboraí e o Gráben de Barra de São João.

Recentemente Zalán \& Oliveira (2005) propuseram o modelo genético evolutivo para o Sistema de Riftes Cenozoicos do Sudeste do Brasil (SRCSB), no qual os autores reúnem uma série de eventos geológicos atuantes durante as suas fases de desenvolvimento. O primeiro evento relacionase ao deslocamento da Placa Sul-Americana para oeste sobre uma anomalia térmica durante o Neocretáceo. Esta migração da placa gerou o soerguimento contínuo do embasamento cristalino e a intrusão de stocks alcalinos. No final do Cretáceo Superior, os processos ascensionais ocasionaram o soerguimento e a dissecação do megaplanalto. Com a estabilização do nível de base, as atuações dos processos erosivos propiciaram o aplainamento e a formação da superfície de erosão Japi. Reativações tectônicas tardias, ocorridas durante o Paleógeno originaram a individualização das unidades morfológicas da Serra do Mar, devido à instabilidade gravitacional dos blocos e movimentações verticais diferenciais, ocasionando uma acentuação dos processos denudacionais nos relevos da Serra do Mar.

Na porção adjacente à margem continental composta pelas bacias marginais brasileiras, a evolução tectônica ocorrida durante o Mesozoico-Cenozoico propiciou o processo de fragmentação do Continente Gondwana. Este processo foi caracterizado no segmento sul e sudeste da margem continental brasileira pelo vulcanismo basáltico presentes na Província do Paraná, nos arcos de Rio Grande, Ponta Grossa e o Platô de São Paulo, devido à forte influência da pluma mantélica de Tristão da Cunha no soerguimento e desenvolvimento do Rift Sul-Atlântico (BUENO, 2004). 
Após o processo de abertura do Atlântico Sul, parte da crosta na porção oeste da Bacia de Campos sofreu estiramento litosférico, resultando no afinamento crustal e subida do manto na área (MOHRIAK et al., 1990, MEISLING et al., 2001). Estes mecanismos ocorreram na margem continental atlântica entre o Jurássico e o Terciário Inferior, culminando com os processos distensivos que afetaram a Plataforma Sul-Americana (ESTRELLA, 1972; ALMEIDA, 1986; CONCEIÇÃO et al., 1988; MOHRIAK, 2004).

Geomorfologicamente a Serra do Mar é composta por um conjunto de planaltos que se distribuem paralelamente à linha de costa, com altitudes médias de 1000 metros e alguns setores, por exemplo, o Planalto da Bocaina, chegando a atingir 2000 metros de altitude (PONÇANO et al., 1981).

Dentro do contexto regional das características geomorfológicas, a área de estudo é formada pelo Planalto do Paraitinga, Paulistano e Juqueriquerê, segundo as definições apresentadas por Ponçano et al., (1981), e Planalto de Moraes, segundo Campanha et al., (1994).

O Planalto do Paraitinga é caracterizado por uma região drenada pela Bacia do Rio Paraíba do Sul a montante do município de Guararema, estabelecendo-se nos limites entre os estados de São Paulo e Rio de Janeiro, próximo ao começo do Planalto da Bocaina. Morfologicamente trata-se de um planalto cristalino, maturamente dissecado, composto por relevos de "mar de morros" e longas serras longitudinais. Segundo Almeida (1964), suas altitudes decrescem para WSW, chegando a alcançar até 1300 metros, com amplitudes locais de relevo que atingem 200 a 300 metros.

O Planalto Paulistano corresponde a uma área de cerca de $5000 \mathrm{~km}^{2}$ composto por morros e interflúvios com altitudes médias em torno de 715 a 900 metros, decrescendo suavemente de sudeste para noroeste (PONÇANO et al., 1981). Em seu trecho centro-norte, aloja-se a bacia sedimentar de São Paulo, através da qual drenam as águas do Rio Tietê e de alguns de seus principais afluentes.

$\mathrm{Na}$ área próxima à região entre Guararema e Salesópolis (SP) foi denominado localmente de Planalto de Moraes por Campanha et al., (1994), por se tratar de um planalto mais elevado e constituir a área de nascente do Rio Tietê. O Planalto do Moraes parece integrar ou se faz parte integrante do Planalto Paulistano, como definido por Almeida (1964). Entretanto, tendo em vista que a área em análise é restrita e associada ao importante divisor de águas Tietê-Paraibuna não se pode descartar a hipótese de se tratar de um remanescente de uma fase erosiva anterior à instalação do Planalto Paulistano, ou seja, de um relevo cujos níveis topográficos superiores atingem altitudes relacionadas à posição da Superfície SulAmericana soerguida. Em sua porção sudoeste, o Planalto do Moraes apresenta limite abrupto com a Província Costeira composta por escarpas festonadas de grande amplitude da Serra do Mar.
O Planalto de Juqueriquerê está inserido no contexto geomorfológico da Província Costeira, segundo as divisão proposta por Ponçano et al., (1981). Regionalmente o Planalto de Juqueriquerê é formado por morros subnivelados com altitudes entre 700 e 750 metros, colocado cerca de 200 metros abaixo do Planalto do Paraitinga e 500 metros abaixo em relação ao Planalto Paulistano.

\section{Metodologia}

\section{Mapeamento dos níveis de paleossuperfícies}

O termo paleossuperfície pode ser definido como a forma de relevo que não está de acordo com as condições climáticas e tectônicas atuais. Estas paleossuperfícies podem estar parcialmente fragmentadas ou reformuladas, mas que de maneira geral ainda podem ser reconhecidas em suas formas originais (WIDDOWSON, 1997). Algumas questões relativas à escala de trabalho aparecem implícitas no termo paleossuperfície, como, por exemplo, em todas as superfícies geomorfológicas identificadas, estas possuem um intervalo de tamanho e dimensão específica (por exemplo, terraços fluviais), sendo que através desta escala de erosão continental ou regional, estas unidades morfológicas podem ser caracterizadas como paleossuperfícies, enquanto que as formas morfológicas que apresentam feições de pequena a média escala, normalmente não estão sujeitas à pesquisa de paleossuperfícies, devido a pouca durabilidade e preservação das superfícies em áreas restritas, bem como as dificuldades apresentadas no reconhecimento de superfícies mais antigas. Em morfologias que exibem feições de grande escala, normalmente estas requerem períodos de tempo mais longos para formarem estas extensas superfícies, que são comumente consideradas como níveis de paleossuperfícies. Geralmente feições morfológicas desta natureza exibem uma melhor durabilidade em relação a outros níveis erosivos que foram geradas em um intervalo de tempo menor (WIDDOWSON, 1997).

Os níveis de paleossuperfícies que apresentam maiores extensões têm sido reconhecidos como um importante componente da paisagem, envolvendo questões sobre qual tipo de ambiente esta se originou, o seu desenvolvimento e subsequente preservação, representando um aspecto crucial para os modelos de evolução da paisagem a serem empregados. Muitos modelos geomorfológicos buscam explicações para a formação lateral de extensas superfícies erosivas, considerando os diferentes tipos de processos geomorfológicos e conceitos como a peneplanação (DAVIS, 1899), pedimentação (PENCK, 1953, KING, 1953) e etchplanação (THOMAS, 1974, 1994). Outros modelos de evolução da paisagem propõem a existência de diferentes níveis de paleossuperfícies, devido às variações tectônicas e climáticas em que as mesmas foram geradas (HILLS, 1961; FAIRBRIDGE \& FINKL, 1980; BÜDEL, 1982; BREMER, 1985; OLLIER, 1985). 
Grande parte das paleossuperfícies é caracteristicamente de origem subaérea, tendo como resultado uma associação direta com os depósitos residuais. A maioria das pesquisas sobre paleossuperfícies associam estes resultados juntamente com o exame sobre a evolução de depósitos de lateritas, silcretes e calcretes (MCFARLANE, 1976; BOWDEN, 1997). Este tipo de associação deve-se à preservação dos níveis de paleossuperfícies e o desenvolvimento de depósitos lateríticos muitas vezes como um pré-requisito para uma exposição subaérea mais lenta, caracterizado por um período de quiescência tectônica e um aumento no grau de estabilidade climática. Entretanto, deve ser lembrado que no caso dos depósitos de bauxita, fatores como tamanho, espessura e o surgimento de um horizonte laterítico mais endurecido costumam surgir após a formação do nível de paleossuperfície, resultante dos processos de epirogenia e, por isso, nem sempre devem ser consideradas contemporâneas com a formação do nível de paleossuperfície (MCFARLANE, 1983; THOMAS, 1994).

Uns dos fatores de maior relevância para os estudos em grande escala abordando os níveis de paleossuperfícies têm sido empregados diretamente sobre a sua influência na sedimentação das bacias marginais adjacentes e na porção continental por meio do controle nas mudanças nos suprimentos de sedimentos, regimes fluviais e rejuvenescimento da paisagem (WIDDOWSON, 1997, SUMMERFIELD, 2005). No entanto, um dos principais problemas em se estudar os níveis de paleo-superfícies é a determinação da idade dos mesmos. Em alguns casos, onde as superfícies são preservadas juntamente com um nível estratigráfico com cronologia conhecida, uma estimativa sobre a idade pode ser realizada por meio da datação das litologias adjacentes a estes níveis de erosão, seja por meio de métodos paleontológicos ou geocronológicos. Alguns estudos podem auxiliar na determinação sobre a cronologia relativa dos níveis de paleosuperfícies, onde estes muitas vezes possuem uma evolução policíclica associada a mudanças relacionadas às suas condições tectônicas e climáticas durante sua história evolutiva. Neste artigo trabalho foram utilizados os dados disponíveis no website do Serviço Geológico dos Estados Unidos (USGS/EROS Data Center), do qual foram extraídas as imagens SRTM (Shuttle Radar Topography Mission) que possibilitaram gerar modelos digitais de terreno com resolução de aproximadamente 90 metros. A correção dos dados do SRTM foi realizada com o auxílio da base cartográfica digitalizada no programa AutoCAD R14 da área de estudo, utilizando a carta topográfica de Santos na escala 1:250 000. A partir da confecção da base digital foi confeccionado o mapa de contorno. Para a confecção do mapa de níveis de paleossuperfícies foram utilizadas as metodologias proposta por Lidmar-Bergström (1996) e Bonow et al., (2003, 2006), onde foram extraídas as curvas de nível que provavelmente representam os níveis de paleossuperfícies horizontais ou sub-horizontais em relação ao nível de base local. O mapa de níveis de paleossuperfícies foi dividido em intervalos de 200 metros, representando os principais níveis de erosão da área de estudo. Foram identificados três níveis de paleossuperfícies situados entre $1400 \mathrm{e}$ 1000 metros, o segundo entre 900 e 700 metros e o terceiro entre 600 e 200 metros.

\section{Termocronologia de baixa temperatura}

\section{Análise de Traços de Fissão em Apatitas}

O método de datação por traços de fissão baseia-se na análise de defeitos ou "traços" causados pela fissão espontânea do ${ }^{238} \mathrm{U}$. Quando este átomo de ${ }^{238} \mathrm{U}$ se fissiona, o mesmo se quebra em duas partículas, liberando energia cinética através do lançamento de dois átomos filhos com direções opostas, responsáveis pela formação dos traços latentes. Os traços latentes são representados pela zona desarranjada "defeitos" no reticulo cristalino do mineral provocada pela passagem dos átomos filhos. Para que os traços latentes possam ser medidos via microscópio óptico são necessários tratamentos químicos prévios.

Neste trabalho foi utilizado o método do detector externo que se baseia na datação de grãos individuais de apatita, permitindo medir a densidade de traços fósseis $\left({ }^{238} \mathrm{U}\right)$ e induzidos $\left({ }^{235} \mathrm{U}\right)$ em cada grão, onde é possível calcular a idade para cada grão analisado. Usualmente o detector externo utilizado é uma lamínula de muscovita, juntamente com a montagem dos grãos de apatita para posteriormente serem irradiados em um reator nuclear com nêutrons térmicos.

As Análises de Traços de Fissão em Apatitas (ATFA) foram realizadas no Instituto de Geociências e Ciências Exatas, Departamento de Petrologia e Metalogenia (UNESP - Rio Claro/SP). Para a análise de TFA, cada amostra foi submetida a um tratamento prévio constituído por etapas de britagem, peneiramento, bateamento manual, separação magnética (por meio do separador magnético do tipo Frantz), separação química do mineral de interesse utilizando líquidos pesados (Bromoformio) e separação dos cristais de apatita em lupa binocular com aumento de 40x. Após este procedimento, os grãos de apatita foram montados em resina do tipo epóxi. Posteriormente, as montagens foram polidas e atacadas quimicamente em uma solução de $\mathrm{HNO}_{3}$ a $7 \%$, sob temperatura controlada de $20^{\circ} \mathrm{C}$ durante 60 segundos, este procedimento visa à revelação dos traços de fissão. Em seguida, foi acoplada em cada amostra uma lamínula de muscovita e submetida à irradiação por nêutrons térmicos para a indução da fissão do ${ }^{235} \mathrm{U}$, cujos traços são detectados pelas lamínulas de muscovita. Ao retornar do reator, as montagens são desfeitas e as micas são submetidas a um ataque químico para revelação dos traços induzidos. As micas são colocadas em uma solução HF $40 \%$ sob temperatura de $15^{\circ} \mathrm{C}$ durante duas horas e meia e neutralizadas em solução de bicarbonato de sódio. Finalizado este processo, as amostras estão prontas para serem contadas e medidas através da utilização do microscópio óptico com aumento de 1000x. 
Para o cálculo das idades de traços de fissão em apatitas foi utilizado o método de calibração Zeta (HURFORD \& GREEN, 1983). Para as modelagens das histórias térmicas foi utilizado o software THA (HADLER NETO et al., 2001), sendo este baseado no modelo empírico desenvolvido por Green et al., (1986), Laslett et al., (1987) e Duddy et al., (1988) e modificado por Tello Saenz (1994). Este software gera histórias térmicas de forma randômica (Método de Monte Carlo), onde os pontos de inflexão são escolhidos em intervalos de tempo e temperatura definidos por meio das caixas de Monte Carlo. Para cada história térmica temos o seu histograma teórico de comprimento de traços calculado e através do teste de $\chi^{2}$ este é comparado ao histograma experimental, se houver homogeneidade entre os histogramas, a história térmica será aceita pelo software. Repetindo-se este procedimento entre 500 e 2000 vezes, por amostra, é usual, pelo menos no início do processo, que algumas amostras tenham histórias térmicas aceitas e outras não. As histórias térmicas aceitas são extremamente importantes por servirem de guia na próxima etapa do processo, onde neste caso podemos diminuir as áreas das caixas de Monte Carlo ou para nova subdivisão destas caixas.

\section{U-Th/He em apatitas}

$\mathrm{O}$ método se baseia na medição do nuclídeo de ${ }^{4} \mathrm{He}$ (partícula $\alpha$ ) que é produzido durante o decaimento radioativo das séries do ${ }^{238} \mathrm{U},{ }^{235} \mathrm{U}$ e ${ }^{232} \mathrm{Th}$ (Farley, 2000), resultando na produção estável de ${ }^{206} \mathrm{~Pb},{ }^{207} \mathrm{~Pb} e^{208} \mathrm{~Pb}$. Uma quantidade insignificante de partículas $\alpha$ também é produzida pelo decaimento do ${ }^{147} \mathrm{Sm} /{ }^{144} \mathrm{Nd}$, gerando os nuclídeos radiogênicos de ${ }^{143} \mathrm{Nd}$, ${ }^{140} \mathrm{Ce}$, respectivamente. Estudos laboratoriais sobre as medidas de difusão do gás hélio indicaram que o hélio radiogênico é retido na apatita sob temperaturas médias da superfície da terra $\left( \pm 45^{\circ} \mathrm{C}\right)$, mas é em ambientes com altas temperaturas que a perda por difusão é maior (ZEITLER et al., 1987, LIPPOLT et al., 1994; WOLF et al., 1996). Como consequência, as idades de $\mathrm{U}-\mathrm{Th} / \mathrm{He}$ em apatitas são sensíveis a temperaturas muito baixas $\left(<100^{\circ} \mathrm{C}\right) \mathrm{e}$, em muitos casos, registram detalhes sobre a história de resfriamento da apatita, pois as idades de hélio neste mineral são sensíveis a temperaturas menores do que outros termocronômetros, consequentemente gera o fornecimento de novas informações sobre a evolução das rochas sob diferentes condições de temperatura versus tempo (WOLF et al., 1996).

Um dos principais problemas encontrados no sistema (U-Th)/He ocorre durante o decaimento radioativo, no qual as partículas $\alpha$ produzidas pelo decaimento do $\mathrm{U}$ e Th são emitidas com uma energia cinética suficiente para atravessar muitos microns através da matéria sólida antes de se neutralizar (FARLEY et al., 1996). Uma consequência deste processo é a segregação espacial entre os elementos pais e filhos, na qual a escala rochosa é negligenciada (FARLEY et al., 1996). Isto pode levar a áreas de manifestações de idades mais antigas ou mais novas. A existência de cristais zonados pode exercer um forte controle da distribuição de hélio, pois os efeitos da zonação presente nos minerais podem afetar na distribuição dos isótopos de $\mathrm{U}$ e Th, influenciando diretamente no controle de dissipação da partícula $\alpha$. Para minimizar estes efeitos, Farley et al., (1996) introduziu uma técnica de correção $\left(\mathrm{F}_{\mathrm{T}}\right)$. Esta técnica baseia-se no princípio que a distribuição de U e Th são uniformes nos cristais, minimizando erros nas idades de (U-Th)/He.

\section{Separação dos cristais de apatita para a datação por (U-Th)/He}

Para a obtenção dos grãos de apatitas foram realizados todos os procedimentos adotados visando à concentração de minerais pesados (apatita+zircão). Posteriormente estes concentrados foram novamente repassados no separador magnético do tipo "Frantz", com intuito de se eliminar os grãos de apatitas que possuem uma grande quantidade de inclusões minerais.

Após esta etapa, deu-se início dos processos de catação manual em uma lupa binocular com aumento de 40 vezes. Durante este procedimento foram selecionados grãos de grãos de apatitas com as mesmas características físicas (tamanho e forma).

Foram separadas duas amostras de apatitas, contendo aproximadamente cem grãos de apatita para cada amostra, seguindo os procedimentos acima descritos. As amostras posteriormente foram enviadas para análise de (U-Th)/He na Universidade do Kansas (EUA)-Departamento de Geologia no Laboratório de (U-Th)/He sob os cuidados do Prof. Dr. Daniel Stockli.

\section{Resultados e discussões}

\section{Análise geomorfológica}

De acordo com as análises geomorfológicas realizadas na porção central da Serra do Mar (Figura 1), os relevos encontram-se compartimentados em três níveis de paleossuperfícies distintos (Figura 2).

O primeiro nível de paleossuperfície com altitudes entre 1400 e 1000 metros, formado pelo Planalto de Moraes, onde se situa a nascente do Rio Tietê. Este nível de paleossuperfície obedece à direção preferencial nordeste, constituída por cimeiras aplainadas e rochas intensamente intemperizadas.

O segundo nível de paleossuperfície possui intervalo de altitude entre 900 e 700 metros, situado no Planalto de Paraitinga. Estes níveis de paleossuperfícies formam as porções mais elevadas constituídas pelas zonas de interflúvios que compõem as drenagens do Rio Paraitinga. $\mathrm{Na}$ porção mais ao sul do Planalto do Paraitinga, próximo ao divisor principal entre os rios Paraíba do Sul e Paraitinga, os níveis de paleossuperfícies possuem altitudes mais ele- 
vadas, devido à presença de relevos que compõem a zona de transição entre o Planalto de Paraitinga e Paulistano, localmente denominado por Campanha et al., (1994) por Planalto de Moraes.
O terceiro nível de paleossuperfície é formado pelo Planalto de Juqueriquerê com altitudes entre 600 e 200 metros. Topograficamente, este planalto situa-se na porção subjacente ao Planalto de Moraes, formando relevos escalonados em alguns trechos.

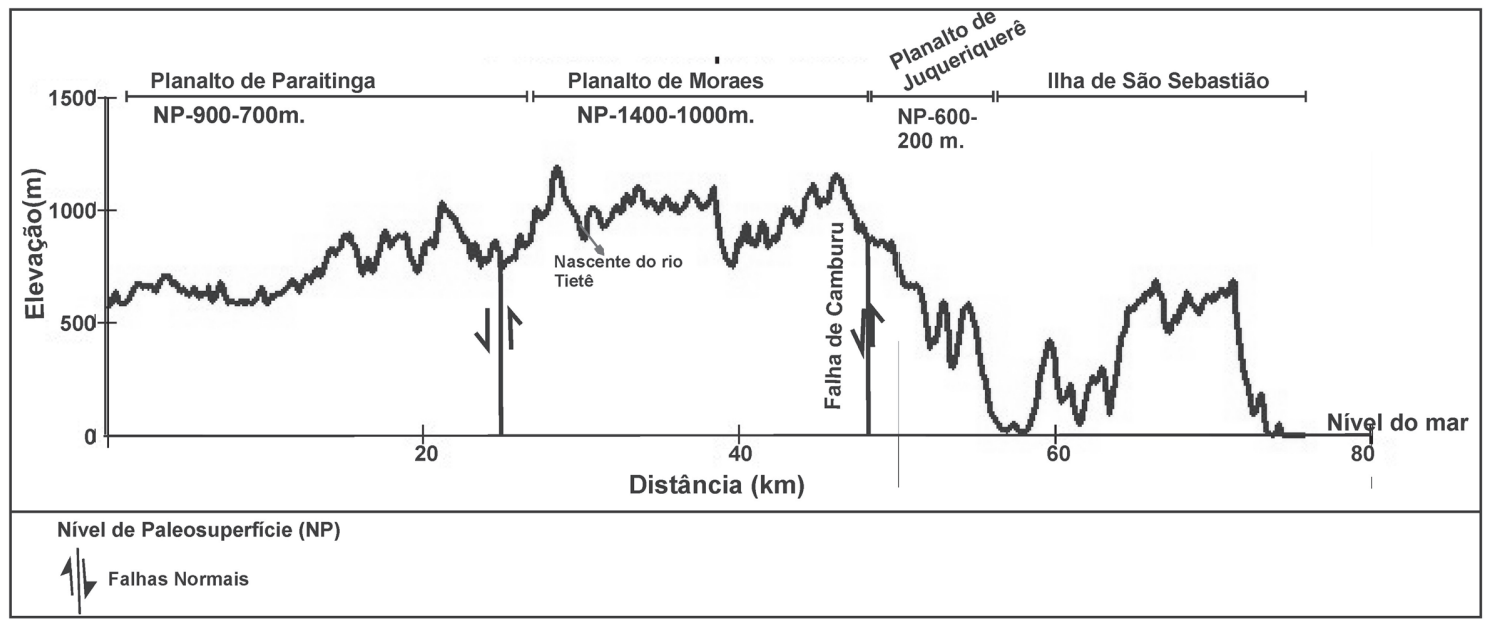

Figura 2 - Perfil mostrando a distribuição dos níveis de paleossuperfícies mapeados e distribuição das amostras coletadas para análises de ATFA e (U-Th)/He em apatitas (Fonte: Carta Topográfica Santos escala 1:250.000, IBGE, 1975).

\section{Correlação das análises geomorfológicas e termocro- nológicas na porção central da Serra do Mar}

As ATFA e (U-Th)/He em apatitas apresentaram dois grupos de idades com intervalos distintos (Cretáceo Superior e Paleoceno) (Tabelas 1 e 2) nos três níveis de paleossuperfícies mapeados (Figura 3a). As análises das distribuições das idades dos termocronômetros utilizados levaram em consideração os intervalos de erros calculados. Os resultados de (U-Th)/He em apatitas apresentaram idades mais antigas do que as idades das ATFA (Tabelas 1 e 2). Estes resultados, provavelmente estão associados à rápida passagem pela zona de retenção parcial da sistemática (U-Th)/He em apatitas, gerando uma perda parcial de ${ }^{4} \mathrm{He}$ nas apatitas. Segundo Stockli et al., (2000) e Emmel et al., (2007), estes períodos de perda parcial de ${ }^{4} \mathrm{He}$ por difusão no sistema (U-Th)/He em apatitas são marcados pela sobreposição de idades ou idades mais antigas entre ATFA e (U-Th)/He em apatitas. Segundo Stockli et al., (2000) estes resultados geralmente estão correlacionados a exposição das amostras a fontes termais (exemplos: eventos magmáticos) ou áreas que sofreram intenso tectonismo.

Tabela 1 - Dados de ATFA. Legenda: n- número total de grãos analisados; $N$ - número de traços confinados medidos; $\rho_{\mathrm{s}}$ / $\rho_{\mathrm{I}}$ - razão entre a densidade traços espontâneos e induzidos; $\mathrm{CMT}{ }_{(\mu \mathrm{m})-}$ Comprimento médio dos traços confinados, Idade (TFA) Traços de Fissão em Apatitas. As idades de TFA foram calculadas utilizando o fator Zeta de $286 \pm 5$ para o dosímetro IRMM.

\begin{tabular}{|c|c|c|c|c|c|c|c|c|}
\hline Amostra & Latitude $\left({ }^{\circ} \mathbf{S}\right)$ & Longitude $\left({ }^{\circ} \mathbf{W}\right)$ & $\begin{array}{c}\text { Elevação } \\
(\text { metros })\end{array}$ & Litologia & $\mathbf{n}(\mathbf{N})$ & $\rho_{\mathbf{s}} / \rho_{i}$ & $\begin{array}{c}\text { CMT } \\
(\mu \mathrm{m})\end{array}$ & $\begin{array}{c}\text { Idade TFA } \\
(\mathbf{M a})\end{array}$ \\
\hline TF-652 & $23^{\circ} 07^{\prime} 04^{\prime \prime}$ & $45^{\circ} 13^{\prime} 40^{\prime \prime}$ & 753 & Gnaisse & $46(48)$ & 1.50 & 11.61 & $89.8 \pm 7.6$ \\
\hline TF-653 & $23^{\circ} 09^{\prime} 01^{\prime \prime}$ & $45^{\circ} 14^{\prime} 48^{\prime \prime}$ & 747 & Ortognaisse & $54(33)$ & 0.69 & 11.84 & $54.5 \pm 4.8$ \\
\hline TF-655 & $23^{\circ} 25^{\prime} 09^{\prime \prime}$ & $45^{\circ} 32^{\prime} 01^{\prime \prime}$ & 710 & Granodiorito & $31(25)$ & 0.73 & 11.56 & $77.7 \pm 9.7$ \\
\hline TF-657 & $23^{\circ} 30^{\prime} 15^{\prime \prime}$ & $45^{\circ} 38^{\prime} 48^{\prime \prime}$ & 655 & Gnaisse & $24(16)$ & 0.65 & 11.23 & $50.4 \pm 6.1$ \\
\hline TF-660 & $23^{\circ} 32^{\prime} 21^{\prime \prime}$ & $45^{\circ} 42^{\prime} 33^{\prime \prime}$ & 843 & Granito & $52(29)$ & 1.12 & 11.92 & $68.5 \pm 5.6$ \\
\hline TF-661 & $23^{\circ} 35^{\prime} 40^{\prime \prime}$ & $45^{\circ} 44^{\prime} 08^{\prime \prime}$ & 1027 & Migmatito & $64(16)$ & 1.02 & 12.06 & $61.0 \pm 4.8$ \\
\hline TF-665A & $23^{\circ} 44^{\prime} 25^{\prime \prime}$ & $45^{\circ} 33^{\prime} 50^{\prime \prime}$ & 639 & Granito & $32(09)$ & 1.14 & 12.42 & $81.8 \pm 8.0$ \\
\hline TF-665B & $23^{\circ} 44^{\prime} 25^{\prime \prime}$ & $45^{\circ} 33^{\prime} 50^{\prime \prime}$ & 639 & Sienito & $86(13)$ & 0.71 & 12.35 & $50.4 \pm 3.6$ \\
\hline
\end{tabular}


Tabela 2 - Idades de (U-Th)/He em apatitas. Legenda: N - número de grãos analisados; U - teor de Urânio medido; Th - teor de Tório medido; Sm - teor de Samário medido; Th/U - razão entre os isótopos de Tório e Urânio, He (nce/ mg) - quantidade de ${ }^{4} \mathrm{He}$ total extraído; mg - peso total dos cristais analisados; Ft - correção da idade de (U-Th)/He (segundo Farley, 2002).

\begin{tabular}{|c|c|c|c|c|c|c|c|c|c|}
\hline Amostra & (N) & U (ppm) & Th (ppm) & Sm(ppm) & Th/U & He (nce/mg) & (mg) & Ft & Idade de (U-Th)/He (Ma) \\
\hline TF-656 & 03 & 46.1 & 47.6 & 404.5 & 1.03 & 614.5 & 8.6 & 0.81 & $96.7 \pm 5.8$ \\
\hline TF-665b & 03 & 4.1 & 18.4 & 295.4 & 4.5 & 63.4 & 19.0 & 0.80 & $59.3 \pm 2.1$ \\
\hline
\end{tabular}

A partir das análises realizadas no perfil topográfico foi possível notar um forte desnivelamento topográfico entre os níveis de paleossuperfícies mapeadas entre 1400 e 1000 e 600 e 200 metros. Trabalhos realizados na área por Almeida (1964) e Fúlfaro et al., (1974), Campanha et al., (1994) com destaque para o Planalto do Juqueriquerê, reconheceram a existência do falhamento de Camburu, que limita o Planalto do Juqueriquerê do Planalto de Moraes (Figura 3a), estes autores sugeriram a sua origem associada uma tectônica de abatimentos de blocos durante o Cenozoico.

Nos níveis de paleossuperfícies com altitudes entre 900 e 700 metros não foram encontrados indícios de superfícies erosivas preservadas (Figura 3a), pois este nível encontra-se extremamente intemperizado, apenas próximo à zona de transição entre o Planalto Paraitinga e Paulistano foi possível identificar antigos níveis de paleossuperfícies preservados (Foto 1).

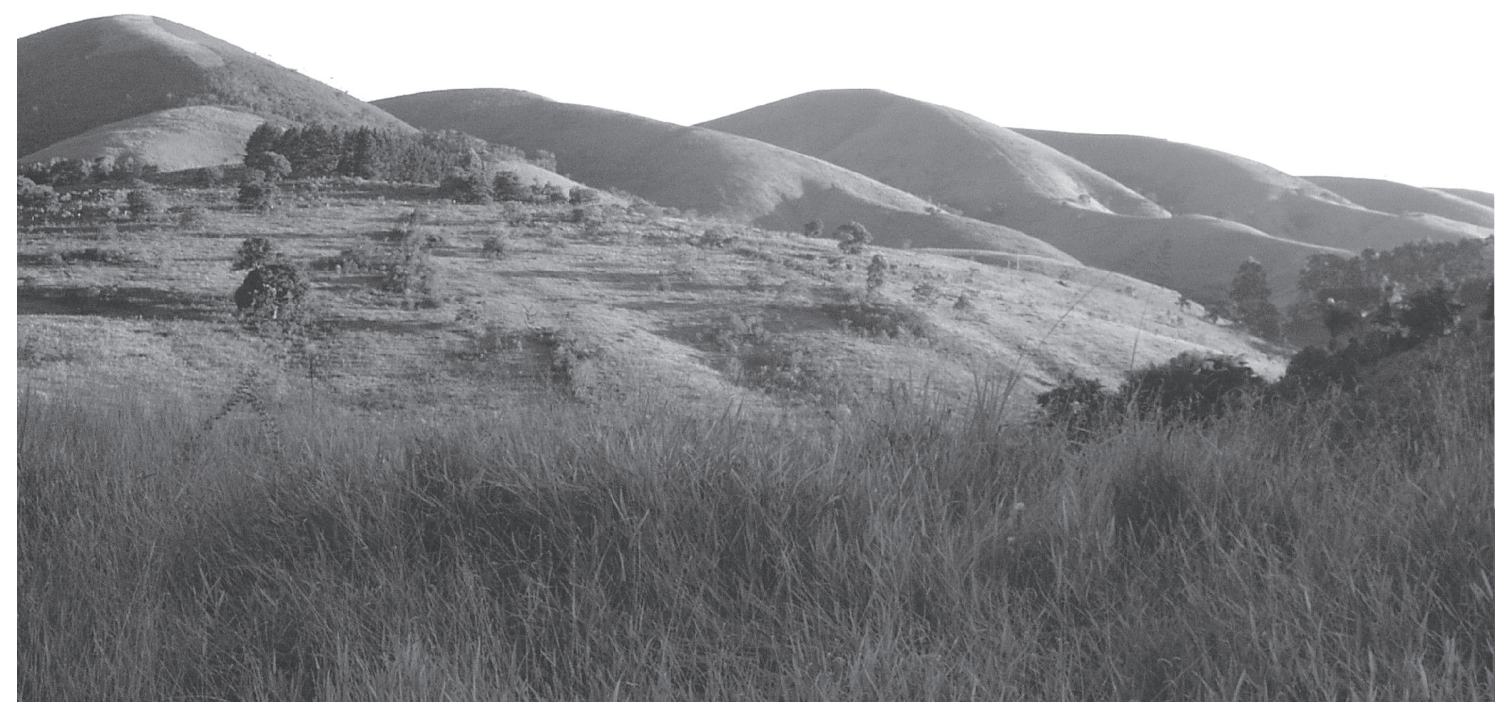

Foto 1: Morfologias situadas na zona de transição entre o Planalto de Paraitinga e Paulistano com nível de paleossuperfície situado no intervalo de altitude de 900 a 700 metros. Rodovia Natividade da Serra-Redenção da Serra (SP). Fonte: Siqueira-Ribeiro (2007).

As correlações entre as análises geomorfológicas e termocronológicas (ATFA) e (U-Th)/He em apatitas permitiram identificar dois períodos distintos que contribuíram na configuração e no desenvolvimento dos níveis de paleossuperfícies, o primeiro datado do Cretáceo Superior e o segundo do Paleoceno.

Na região do Planalto de Paraitinga, onde foram mapeados os níveis de paleossuperfícies com altitudes entre 900 e 700 metros (Figura 3a), foram registradas idades de TFA do Cretáceo Superior e Paleoceno (Figura 3b), enquanto que a idade obtida para a sistemática (U-Th)/He em apatitas apresentou idade do Cretáceo Superior (Figura 3b). Estes resultados indicam que as amostras datadas pela (ATFA) e (U-Th)/He em apatitas resfriaram-se rapidamente, ou seja, passaram rapidamente pela zona de retenção parcial de seus respectivos termocronômetros. Este resfriamento rápido indicado pelas análises termocronológicas demonstra que neste nível de paleossuperfície, as morfologias foram rapidamente soerguidas (exumadas) no Cretáceo Superior, posteriormente estas permaneceram em um estado estacionário, ou seja, não ocorreram mudanças significativas no nível de base, apenas a atuação dos processos erosivos. Provavelmente, as morfologias que compõem o Planalto de Paraitinga foram lentamente formadas no decorrer do Paleógeno. 
As análises das histórias térmicas modeladas neste nível de paleossuperfície indicaram um resfriamento rápido a partir do Cretáceo Superior ao Paleoceno (Figura 3c), após este período, a partir do Paleoceno ao Eoceno, estas se resfriaram lentamente. Por meio da correlação entre as análises dos dados termocronológicos foi possível associar as idades de traços de fissão e os primeiras datações por (U-Th)/He em apatitas com um período em que os relevos da Serra do Mar, especificamente o Planalto de Paraitinga, sofreram um forte alçamento no nível de base no Cretáceo Superior, após este período deu-se início a instalação do ciclo erosivo que atuou na configuração dos relevos que compõem o nível de paleossuperficies com altitudes entre 900 e 700 metros. Este episódio de resfriamento com idades do Cretáceo Superior foi responsável pelo soerguimento em toda porção da Serra do Mar, como anteriormente colocado por Tello et al., (2003) e Hackspacher et al., $(2003,2004)$, através das ATFA, gerando a fragmentação e a dissecação de antigos níveis erosivos.

No nível de paleossuperfície com altitudes situadas entre 1400 e 1000 metros (Figura 3a), formadas pelo Planalto de Moraes apresentou idade de TFA paleocênica, (Figura 3b). Geomorfologicamente, após este evento tectônico no Paleoceno, parte do Planalto Paulistano foi compartimentado em decorrência das reativações de antigos falhamentos, formando o que viria a constituir atualmente os relevos do Planalto de Moraes. Trabalho realizado por Campanha et al.(1994) afirma que o Planalto de Moraes provavelmente foi desnivelado por falhamentos normais, contudo não foram observadas falhas que justificassem essa hipótese, embora as direções N-S e NW-SE correspondam às direções subordinadas dos sistemas de juntas, espelhos de falhas e da orientação de diques observados na área. Embora os autores não afirmem a atuação de falhamentos condicionando a distribuições entre as diferentes morfologias, as modelagens de histórias térmicas indicaram um resfriamento rápido no limite Eoceno-Oligoceno (Figura 3d), indicando uma provável atuação tectônica entre ambos.

No nível de paleossuperfície com altitudes entre 600 e 200 metros (Figura 3a), formado pelo Planalto de Juqueriquerê, representado por relevos escalonados, registraram idades de TFA no limite entre o Cretáceo Superior-Paleoceno (Figura $3 b)$, enquanto que apenas uma amostra datada pela sistemática (U-Th)/He em apatitas registrou idade paleocênica. De acordo com os resultados termocronológicos estes se resfriaram na mesma época, ultrapassando rapidamente suas respectivas zonas de retenção parcial. Este resfriamento rápido indicado pelas análises termocronológicas demonstra que as morfologias no Planalto de Juqueriquerê foram rapidamente sobre-elevadas. Segundo Pereira \& Feijó (1994) e Modica \& Brush (2004) reconheceram uma discordância regional na Bacia de Santos em aproximadamente $70 \mathrm{Ma}$, sugerindo uma associação com um possível alçamento do embasamento cristalino adjacente a essa bacia entre o Maastrichiano e Paleoceno Inferior.

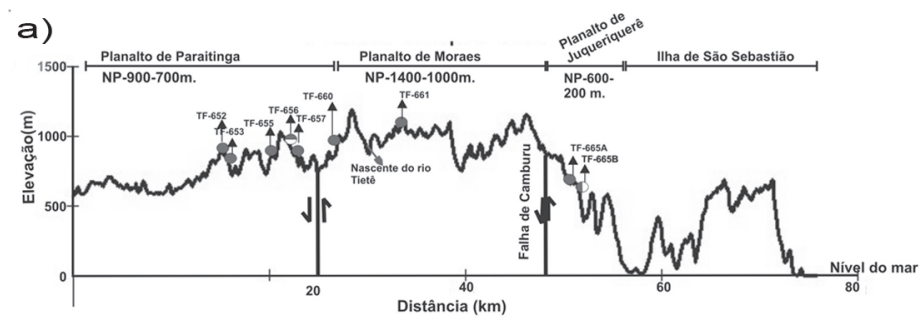

Legenda

- Amostras datadas com(ATFA)

Amostras datadas com(U-Th)/He em apatitas

Amostras datadas com(ATFA) (U-Th)/He em
apatitas

Nivel de Paleo-superfície (NP)

1| Falhas Normais

Distância (km)

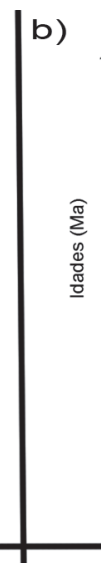

c)

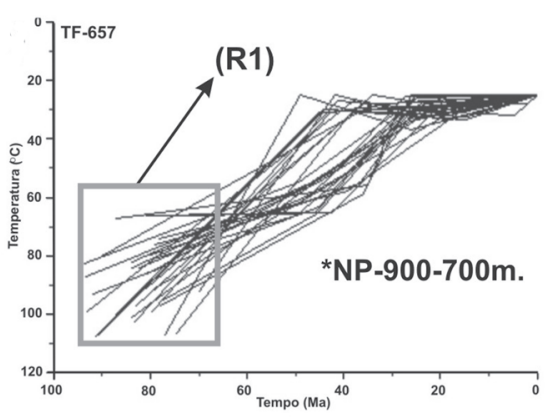

(R1) Fase de resfriamento 1: Cretáceo Superior(R2)Fase de resfriamento 2 Paleoceno-Eoceno. b)

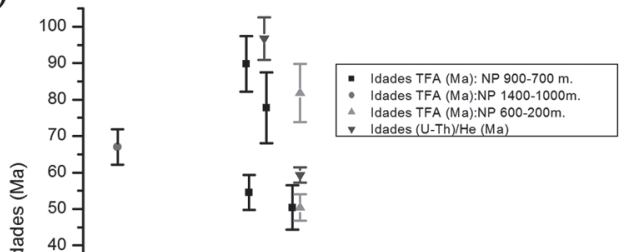

d)

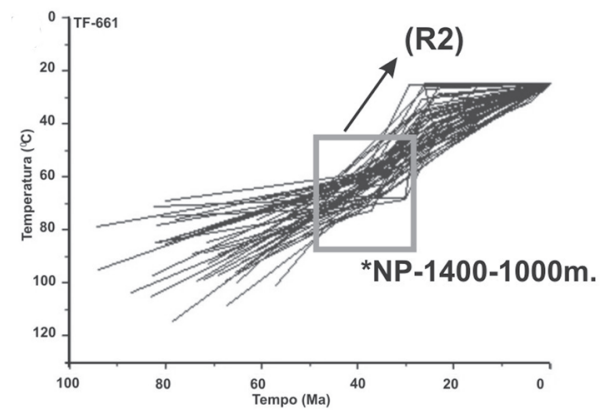

Figura 3: a) Perfil mostrando a distribuição dos niveis de paleossuperficies mapeados; b) Distribuição das idades de Traços de Fissão em apatitas e (U-Th)/He em apatitas; c) História térmica do nivel de paleossuperficie (900-700 metros- TF-657); d) História térmica do nivel de paleossuperficie (1400-1000 metros - TF-661). 


\section{Considerações finais}

Os processos morfogenéticos resultantes deste importante desnivelamento tectônico ocorrido no limite entre Cretáceo Superior-Paleoceno registrado pelas idades ATFA e (U-Th)/ He em apatitas, propiciaram o desmantelamento, a dissecação dos níveis de paleossuperfícies e a reorganização da rede de drenagem dos relevos que até então formavam a Serra do Mar no final do Cretáceo Superior. Após o evento tectônico, ocorrido no Paleoceno, os níveis de paleossuperficies sofreram processos erosivos e de dissecação, que viriam a configurar as drenagens dos planaltos que configuram a Serra do Mar. Outra importante feição que foi sobre-elevada durante o tectonismo paleocênico foi a formação do nível de paleossuperfície com altitudes entre 1400 e 1000 metros, que viriam a constituir os mananciais que compõem a nascente do Rio Tietê. Nesta mesma época, de acordo com Pereira \& Feijó (1994), o registro estratigráfico da Bacia de Santos mostra uma forte discordância erosiva provavelmente relacionada à interrupção das paleodrenagens que até então migrava em direção a borda continental nesta época.

\section{Agradecimentos}

À FAPESP pelo suporte financeiro do projeto temático de equipe (Processo: 00/03960-5) e a bolsa de Doutorado e reserva técnica de Marli Carina Siqueira Ribeiro (Processo: 03/07574-0), ao Prof. Dr. Daniel Stöckli pelas análises de (U-Th) $\backslash \mathrm{He}$ em apatitas realizadas na Universidade do Kansas (EUA) e ao Instituto de Pesquisas Nucleares (IPEN-São Paulo) pelas irradiações das amostras para análise de traços de fissão em apatitas. E especialmente ao Dr. Pedro José Iunes (in memorian) pelo convite para trabalhar com ATFA no ano de 1999, por sua contribuição na arguição e sugestões na minha tese de doutorado e por sua amizade, muito obrigada!

\section{Referências bibliográficas}

ALMEIDA, F. F. M. de. Fundamentos geológicos do relevo paulista. Boletim Instituto de Geografia e Geologia-IGG-USP -São Paulo, v. 41, p. 169-263, 1964.

ALMEIDA, F. F. M. de. Origem e evolução da Plataforma Brasileira. Rio de Janeiro,DNPM-DGM, Boletim, v. 241, p. 36, 1967.

ALMEIDA, F. M. M. de. Diferenciação tectônica da Plataforma Brasileira. In: Congresso Brasileiro de Geologia, 23., 1969, Salvador, Anais...Salvador: Sociedade Brasileira de Geologia, p.29-46, 1969. ALMEIDA, F. F. M. DE. The system of continental rifts bordering the Santos Basin, Brazil. Anais da Academia Brasileira de Ciências, v. 48 (suplemento), p. 15-26, 1976.

ALMEIDA, F. F. M. de. Relações tectônicas das rochas alcalinas mesozoicas na Região Meridional da Plataforma Sul-Americana. Revista Brasileira de Geociências, v. 13(3): p. 139-158, 1983. ALMEIDA, F. M. M. DE. Distribuição regional e relações tectônicas do magmatismo pós-paleozoico no Brasil. Revista Brasileira de Geociências, v. 16(4), p. 325-349, 1986.

ALMEIDA, F. F. M. O alinhamento magmático de Cabo Frio. In: II Simpósio de Geologia do Sudeste, 1991. São Paulo, Atas... São Paulo, Sociedade Brasileira de Geologia, p.423-428, 1991
ALMEIDA, F. F. M.de; HASUI Y.; BRITO NEVES B. B. de, FUCK; R. A. 1977. As províncias estruturais brasileiras. In: SBG, Simpósio de Geologia do Nordeste, 8, Campina Grande, 1977. Atas ... Campina Grande p. 363-391, 1977.

ALMEIDA, F. F. M. de, HASUI Y., PONÇANO W. L., DANTAS A. S. L., CARNEIRO C. D. R., MELO M. S. de, BISTRICHI C. A. Mapa Geológico do Estado de São Paulo, escala 1:500.000, Nota Explicativa. São Paulo, IPT, Monografias 6, v. 1, p.126. (Publ. 184), 1981.

ALMEIDA, F. F. M., CARNEIRO, C. Dal Ré. Origem e evolução da Serra do Mar. Revista Brasileira de Geociências, 28, n. 2. p. 135-150, 1998.

BONOW, J. M., LIDMAR-BERGSTRÖM, K., NÄSLUND, J. $\mathrm{O}$. Palaeosurfaces and major valleys in the area of the Kjølen Mountains, southern Norway-consequences of uplift and climatic change. Norsk Geografisk Tidsskrift-Norwegian Journal of Geography v. 57, p. 83-101, 2003.

BONOW, J. M, LIDMAR-BERGSTRÖM, K., JAPSEN. P. Palaeosurfaces in central West Greenland as reference for identification of tectonic movements and estimation of erosion. Global and Planetary Change, v. 50, p.161-183, 2006.

BOWDEN, D. J. The geochemistry and development of lateritized footslope benches: The Kasewe Hills, Sierra Leone. In: Widdowson M. (ed.). Palaeosurfaces: Recognition, Reconstruction and Palaeoenvironmental Interpretation, Geological Society (London) Special Publication 120, p. 295-305, 1997.

Bremer, H. Randschwellen: a link between plate tectonics and climatic geomorphology. Zeistscrift für Geomorphologie N. F., Supplementband, v. 54, p. 11-21, 1985.

BÜDEL, J. Climatic Geomorphology (Translated from Klima Geomorphologie, (1977). Princeton: Princeton Unviersity Press., p.443, 1982.

BUENO, G. V. Diacronismo de eventos no rifte Sul-Atlântico. Boletim de Geociências da Petrobras, Rio de Janeiro, v. 12, n. 2. p. 203-229, maio/novembro. 2004. Campanha, G. A. C., Hendrik, H., Ponçano, W. L. Análise morfotectônica do Planalto de Juqueriquerê, São Sebastião. Revista Brasileira de Geociências v. 24 (1), p. 32-42,1994.

CAMPANHA G. A. C., SADOWSKY G. R. Tectonics of the southern portion of the Ribeira Belt (Apiaí Domain). Precambrian Research, v. 98, p. 31-51, 1999.

CONCEIÇÃO, J. C. J., ZALÂN, P. V., Wolf, S. Mecanismo e evolução e cronologia do rift Sul-Atlantiano. Boletim de Geociências da Petrobras, v. 2(2/4), pp. 255-265, 1988.

DUDDY, I. R., GREEN, P. F., LASLETT, G. M. Thermal annealing of fission tracks in apatite. 2: Variable temperature behaviour, Chemical Geology (Isotope Geoscience Section), v. 73, p. 2538, 1988.

EMMEL, B., JACOBS, J., CROWHURST, P., DASZNNIES, M. C. Combined apatite fission-track and single grain apatite $(\mathrm{U}-\mathrm{Th}) \backslash$ He ages from basement rocks of central Dronning Maud Land (East Antarticta) - Possible identification of thermally overprinted crustal segments? Earth Planetary Sciences Letters, v. 264. p.72-88, 2007.

ESTRELLA, G. O. O estágio de rift nas bacias marginais do leste brasileiro. In: SBG. Congresso Brasileiro de Geologia, 26, Belém, 1972. Anais... Belém, 1972. v.3, p.29-34, 1972.

FAIRBRIDGE, R. W., Fink1, C.W. Cratonic erosional unconformities and peneplains. Journal of Geology, v. 88, p. 69-86,1980. 
FARLEY, K. A., WOLF, R. A., SILVER, L. T. The effects of long a stopping distances on U-Th/He ages. Geochimica Cosmochimica Acta v. 60, p. 4223-4230, 1996.

FARLEY, K. A. Helium diffusion from apatite: general behavior as illustrated by Durango fluorapatite. Journal Geophysical Research v. 105, p. 2903-2914, 2000.

FRANCO, A. B .F., HACKSPACHER, P. C., GODOY, D. F., RIBEIRO, L. F. B., GUEDES, S. História Térmica do maciço alcalino de Poços de Caldas (SP/MG) e adjacências através da análise da datação por traços de fissão em apatitas. Revista Brasileira de Geociências, v. 35 (3), p. 351-358, 2005.

FÚlfARO, V. J., SUGUIO, K., PONÇANO, W. L. A gênese das planícies costeiras paulistas. In: Congresso Brasileiro de Geologia, 28. Porto Alegre, 1974. Anais... Porto Alegre, 1974, SBG. v. 3, p. 37-42, 1974.

GONTIJO, A. H. F. Morfotectônica do médio vale Rio Paraíba do Sul: região da Serra da Bocaina, estados de São Paulo e Rio de Janeiro. 1999. 259f. (Doutorado em Geociências) Universidade Estadual Paulista, Rio Claro, São Paulo. 1999.

GREEN, P. F., DUDDY, I. R., LASLETT, G. M., HEGARTY, K. A., GLEADOW, A. J. W., LOVERING, J. F. Thermal annealing of fission tracks in apatite. 4. Quantitative modelling techniques and extension to geological timescales. Chemical Geology (Isotope Geoscience), v. 79, p.155-182, 1989.

GUEDES, S., HADLER NETO, J. C., IUNES, P. J., ZUÑIGA, A., TELLO SAENZ, C. A., PAULO, S. R. The use of the U $(n, f)$ reaction dosimetry in the determination of the $\lambda_{f}$ value through fission-track techniques. Nuclear Instruments and Methods in Physics Research A, v. 496, p. 215-221, 2003.

HACKSPACHER, P. C., RIBEIRO, L. F. B., RIBEIRO, M. C. S., HADLER NETO, J. C., IUNES, P. J., TELLO SAENZ, C. A. A origem da Serra do Mar: Termocronologia por Traços de Fissão em apatita. In: $9^{\circ}$ Simpósio Nacional de Estudos Tectônicos,

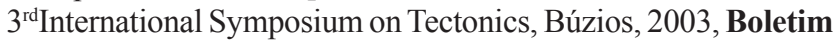
de Resumos... Búzios, SBG, p. 384-386. 2003.

HACKSPACHER, P. C., GODOY, D. F.; RIBEIRO, L. F. B. ; HADLER NETO, J. C.; FRANCO, A. O. B. Modelagem Térmica e Geomorfologia da borda sul do Craton de São Francisco: Termocronologia por traços de fissão em apatita. Revista Brasileira de Geociências, v. 37, p. 76-8/6, 2007.

HACKSPACHER, P. C., Saad, A. R., Hadler Neto, J. C. O registro do limite Cretáceo Superior- Paleógeno em rochas pré- cambrianas da Região Sudeste do Brasil com base em datação por traços de fissão em apatitas. In: $7^{\circ}$ Simpósio do Cretáceo do Brasil e $1^{\circ}$ Simpósio do Terciário do Brasil, Boletim de Resumos... Serra Negra, SBG, p. 65, 2006

HACKSPACHER, P. C; Ribeiro, L. F. B.; Ribeiro, M. C. S.; FETTER, A. H.; HADLER NETO, J. C.; S. TELLO, C. E.; DANTAS, E. L. Consolidation and break-up of the South American platform in southeastern Brazil: tectonothermal and denudation histories. Gondwana Research, v. 1, p. 91-101, 2004.

HAWKESWORTH, C. J., GALLAGHER, K., KIRSTEIN, L., MANTOVANI, M. S. M., PEATE, D. W., TURNER, S. P. Tectonic controls on magmatism associated with continental break-up: an example from the Paraná-Etendeka Province. Earth and Planetary Science Letters, v. 179, p. 335-349, 2000.

HADLER NETO, J. C., IUNES, P. J., PAULO, S. R., TELLO SAENZ, C. A., BALESTRIERI, M. L., Bigazzi, G., Curvo, E.
A. C., Hackspacher, P. C. A PC compatible Brazilian software for obtaining thermal histories using apatite fission track analysis. Radiation Measurements, v. 34, p. 149-154, 2001.

HEILBRON, M., MOHRIAK, W., VALERIANO, C. M., MILANI, E., ALMEIDA, J. C. H., TUPINAMBÁ, M. The roots of the southeastern continental margin Brazil. In: Mohriak, W.U. and Talwani, M. (Eds), Atlantics rifts and continental margins. Washington, American Geophysical Union, Geoph. Monogr. Ser. 115, p. 1-32, 2000.

HILLS, E. S. 1961. Morphotectonics and the geomophological sciences with special reference to Australia. Quarterly Journal of the Geological Society of London, v. 117, p. 77-89, 1961.

HOLDEN, N. E., Hoffman, D. C. Spontaneous fission half-lives for ground-state nuclides. Pure Appl. Chem. v. 72, p. 1525-1526, 2000.

HURFORD, A. J.; GREEN, P. F. The Zeta Age Calibration of fission Track Dating. Chemical Geology, Isotopic Geoscience, v. 1, p. 285-317, 1983.

IBGE - Instituto Brasileiro de Geografia e Estatística - Carta topográfica - São Paulo e Santos - escala 1:250 000 ano 1976.

KING, L. C. Canons of landscape evolution. Geological Society of America Bulletin, v. 64, p. 721-752, 1953.

LASLETT, G. M., GREEN, P. F., DUDDY, I. R., GLEADOW, A. J. W. Thermal annealing of fission tracks in apateite 2. a quantitative analysis. Chemical Geology (Isotope Geoscience Section), v. 65, p. 1-13, 1987.

LIDMAR-BERGSTRÖM, K. Long term morphotectonic evolution in Sweden. Geomorphology, v. 16, p. 33-59, 1996.

LIPPOLT, H. J., LEITZ, M., WERNICKE, R. S., HAGEDORN, B. U-Th.Helium dating of apatite-experience from different geochemical environments. Chemical Geology, v.112, p. 179191, 1994.

MARQUES, L. S., ERNESTO, M. O magmatismo toleítico da Bacia do Paraná. In: MANTESSO-NETO, V.; BARTORELLI, A.; CARNEIRO, C. D. R.; BRITO-NEVES, B. B. (Ed.). Geologia do Continente Sul-Americano: evolução da obra de Fernando Flávio Marques de Almeida. São Paulo: Beca, 2004. p. $245-$ 263.

MCFARLANE, M. J. Laterite and Landscape. Academic, London, p. $176,1976$.

MCFARLANE, M. J. The temporal distribution of bauxitisation and its genetic implications. In: MELFI, A. J., CARVALHO, A. (eds) Lateritisation Processes: Proceedings II International Seminar on Lateritisation Processes, Sao Paulo, Brazil, July 1982, p. 197-207.

MELO, M. S de, RICCOMINI, C., HASUI, Y., ALMEIDA, F. F. M. de, COIMBRA, A. M.. Geologia e evolução do sistema de bacias trafogênicas continentais do sudeste do Brasil. Revista Brasileira de Geociências, v. 15, p. 193-201, 1985.

MEISlinG, K. E., COBBOLD, P. R., MOUNT, V. S. Segmentation of an obliquely-rifted margin, Campos and Santos Basin, southeastern Brazil: AAPG Bulletin, v. 85, nº 11, p. 10931924, 2001.

MIO, E. 2006. Modelagem crustal da Bacia de Santos pela integração de métodos geofísicos. 108f.(Dissertação de Mestrado), Universidade Estadual Paulista, Rio Claro, São Paulo, 2006.

MISUZAKI, A. M. P., THOMAZ FILHO, A., VALENÇA, J. G. 
Volcano sedimentary sequence of Neocomian age in Campos Basin (Brazil). Revista Brasileira de Geociências, v. 18, p. 247-251, 1988.

MIZUSAKI, A. M. P., THOMAZ FILHO, A. O magmatismo póspaleozoico no Brasil. In: V. Mantesso-Neto, A. Bartorelli, C.D.R. Carneiro, B.B. Brito-Neves, orgs. Geologia do Continente SulAmericano: Evolução da obra de Fernando Flavio Marques de Almeida, São Paulo, Beca, p. 281-291, 2004.

MODENESI-GAUTTIERI, M. C. ; HIRUMA, S. T.; RICCOMINI, C. Morphotectonics of a high plateau on the northwest flank of the Continental rift of Southeastern Brazil. Geomorphology (Amstrerdam), Inglaterra, v. 43, n. 3-4, p. 257-271, 2002.

MODICA, J. C. \& BRUSH, E. Postrift sequence stratigraphy, paleogeography,and fill history of the deep-water Santos Basin, offshore southeast Brazil. AAPG Bulletin, v. 88(7), p. 923-945, 2004.

MOHRIAK, W. U., BARROS, A. Z. N., 1990. Novas evidências de tectonismo cenozoico na Região Sudeste do Brasil: o gráben de Barra de São João na Plataforma de Cabo Frio/RJ, Revista Brasileira de Geociências, v. 20, p. 187-196, 1990.

MOHRIAK, W. U. Recursos energéticos associados à ativação tectônica mesozoico-cenozoica da América do Sul. In: MANTESSO-NETO, V.; BARTORELLI, A.; Carneiro, C. D. R.; BRITO-NEVES, B. B. (Ed.). Geologia do Continente SulAmericano: evolução da obra de Fernando Flávio Marques de Almeida. São Paulo: Beca, p. 293-318, 2004.

OLLIER, C. D. Morphotectonics of continental margins with great escarpments. In: M.Morisawa and J.T.Hack (eds) Tectonic Geomorphology, Allen and Unwin, Boston, p. 3-25,1985.

PENCK, W. Morphological analysis of landforms. London, Macmlland, 200p., 1953.

PEREIRA, M. J., FEIJÓ, F. J. Bacia de Santos. Boletim de Geociências da Petrobras, v. 8(1), p. 219-234, 1994.

PONÇANO, W. L., CARNEIRO, C. D. R., BISTRICHI, C. A., ALMEIDA, F. F. M., PRANDINI, F. L. Mapa geomorfológico do Estado de São Paulo. São Paulo. Instituto de Pesquisas Tecnológicas do Estado de São Paulo, v. 2, p. 94, 1981.

RENNE P. R., GLEN J. M., MILNER S. C., DUNCAN A. R. Age of Etendeka flood volcanism and associated intrusions in southwestern Africa. Geology, v. 24, p. 659-662, 1996.

RIBEIRO, L. F. B., HACKSPACHER, P. C., RIBEIRO, M. C. S., HADLER NETO, J. C., TELLO SAENZ, C. A. S., IUNES, P. J., FRANCO, A. O. B., GODOY, D. F. Thermotectonic and fault dynamic analysis of Precambriam basement and tectonics constraints with the Paraná basin. Radiation Mensurements (39), p. $669-673,2005$.

RICCOMINI, C. 1989. O Rift continental do sudeste do Brasil. 1989. 190f (Doutorado em Geologia Sedimentar)-Instituto de Geociências, Universidade de São Paulo, São Paulo,1989.

RICCOMINI, C; SANT'ANNA, L. G.; FERRARI, A. L. Evolução geológica do rift continental do Sudeste do Brasil. In: Mantesso-Neto, V.; BartorellI, A.; Carneiro, C.D.R.; BritoNeves, B. B. (eds.). Geologia do continente Sul-Americano: evolução da obra de Fernando Flávio Marques de Almeida. São Paulo: Beca, 2004a, p. 383-405.

RICCOMINI, C., VELÁZQUEZ, V. F., GOMES, C. B. Tectonic controls of the Mesozoic and Cenozoic alkaline magmatism in central-southeastern Brazilian Platform. In: P.CominChiaramonti, C.B. Gomes (eds). Mesozoic to Cenozoic alkaline magmatism in the Brazilian Platform. EDUSP-FAPESP, São Paulo, 2004b. p. 1-26.

SIQUEIRA-RIBEIRO, M. C. 2007. Termocronologia e História Denudacional da Serra do Mar e implicações no controle deposicional da Bacia de Santos. $201 \mathrm{f}$. (Doutorado em Geociências) - Universidade Estadual Paulista, Rio Claro, São Paulo, 2007.

STOCKLi, D. F., FARLEY, K. A., DUMitri, T. A. CALIBRATION of the apatite (U-Th)/He thermochronometer on an exhumed fault block, White Mountains, California. Geology, v. 28, nº 11 , p. 983-986, november 2000 .

SUMMERFIELD, M. A. The changing landscape of geomphology. Earth Surface Processes and Landforms, 30, p. 779-781, 2005.

SRTM images. Disponível em:http:// www.seamless.usgs.gov/ website/seamless. 2002.(Seamless Data Distribution System, Erth Resources Observation and Science (EROS), (USGS). Acesso em 10 de junho de 2009.

TELLO SAENZ, C. A. 1994. Termocronologia de algumas regiões brasileiras através da análise de traços de fissão em apatitas.100f.(Mestrado em Física), Universidade Estadual de Campinas, Campinas, 1994.

TELLO SAENZ, C. A., HACKSPACHER, P. C., HADLER NETO, J. C., IUNES, P. J., GUEDES, S., PAULO, S. R., RIBEIRO, L. F. B. Recognition of Cretaceous, Paleocene and Neogene Tectonic Reactivation, through Apatite FissionTrack Analysis, in: Precambrian areas of the Southeast Brazil: Association with the South Atlantic Ocean Opening. Journal of South American Earth Science, 15, p. 137-142, 2003.

THOMAS, M. A. Tropical Geomorphology. Macmillan, London and halstead, New York, 457p, 1994.

THOMAS, M. F. Geomorphology in the Tropics - a study of weathering and denudation in low latitudes. John Wiley \& Sons, Chichester, 460p, 1994.

TURNER, S., REGELOUS, M., HAWKESWORTH, C., MANTOVANI, M. Magmatism and continental break-up in the South Atlantic: high precision ${ }^{40} \mathrm{Ar}-{ }^{39} \mathrm{Ar}$ geochronology. Earth and Planetary Sciences letters, 121 (3-4), p. 333-348, 1994. VIEIRA, R. A. B., MENDES, M. P., VIEIRA, P. E., COSTA, L. A. R., TAGLIARI, C. V., BACELAR, L. A. P., FEIJÓ, F. J. Bacias do Espírito Santo e Mucuri. Boletim de Geociências da Petrobrás, 8 (1), p. 191-202, 1994.

ZALÁN, P. V. \& OLIVEIRA, J. A. B. de,. Origem e evolução estrutural do sistema de rifte Cenozoicos do Sudeste do Brasil. Boletim de Geociências da Petrobras, 13, n.2, p. 269-300, 2005. WIDDOWSON, M. Topography, palaeosurfaces and denudation over the Karnataka Uplands, southern India. In: Palaeosurfaces: Recognition, Reconstruction and Palaeoenvironmental Interpretation, WIDDOWSON M. (ed.). Geological Society (London) Special Publication. 120, p. 221-248, 1997.

WOLF, R. A., FARLEY, K. A., SILVER, L. T. Helium diffusion and low temperature thermochronometry of apatite. Geochim. Cosmochim. Acta, 60, p. 4231-4240, 1996.

ZEITLER, P. K., HERCZEG, A. L, MCDOUGALL, I., HONDA, M. U-Th-He dating of apatite: a potential thermochronometer. Geochim. Cosmochim. Act, 51, p. 2865-2868, 1987. 